\title{
Study on the Methods of Media Literacy Training for College Students in the Times of Public Media
}

\author{
Shi Ming \\ School Network Security and Informatization, Weinan Normal University, Weinan, Shaanxi, 714099
}

Keywords: Public Media Era, Media Literacy of College Students, Cultivation Path

\begin{abstract}
In order to cultivate skilled talents to meet needs of building a well-off society, in the face of the media era, constantly updated, perplexing media environment, higher vocational colleges should conform to the trend of the times. The paper analyzes of media literacy of college students and the status quo of cultivation, clarifies the importance of the cultivation of media literacy, so as to explore the effective path of college students' media literacy training, improve their information literacy and media awareness.
\end{abstract}

\section{A Summary of Media Literacy Training}

After the concept of media literacy was put forward, media literacy training is not only out. Because the media literacy has not been a unified definition, so the concept of media literacy education has not formed a unified understanding, like the American scholar Renee Hobbs said: "it is a one thousand name children: a study of visual literacy, media education, media literacy, media, and more." Moreover, due to the differences in political, economic, historical and cultural development and educational ideas among different countries, the cultivation of media literacy can not be a unified and standard definition of the world [1]. "Media literacy training is based on the popularization of popular media in the information age under the stimulation of business motivation, and the education idea which is misled by the popular culture's moral guidance and spiritual pursuit of the people. The definition of domestic scholars agree as follows: media literacy training process is the guidance to the public the correct understanding and constructive access to the mass media resources, through this process, cultivate the public health with the media criticism capacity and morality, which can make full use of media resources to develop themselves and improve themselves, participate in social development. In all media era, in the face of a large amount of information to the college students' media literacy training should focus on the cultivation of College Students' thinking ability and the ability to actively participate in, through the media literacy education, make students know more about the media and media information, receiving critical and improve ability to distinguish media information, in order to minimize the negative impact of bad information on the causes of the [2]. It can be said that the cultivation of the independent personality and healthy mentality of the citizens of the democratic society is the most fundamental purpose of the cultivation of media literacy.

\section{The Importance of Cultivating Media Literacy for College Students in the Age of Public Media}

\subsection{The internal demands of the overall development of College Students}

All kinds of new media all media era has brought a positive impact on college students for college students at the same time, also caused many negative effects: new media more and more entertainment by dispersing the students' attention, have a bad effect on their learning; micro consumerism orientation and the media shopping channel media excessive diversification, make students too much time and energy wasted in the selection of goods, the consumer behavior is distorted; students with too much time on the use of micro media, in the real space "isolation", which can not be self-enclosed, well into the social media; rampant violence and pornography 
information, has done harm to measure of physical and mental health of college students, such as violence, abuse and even work in a relationship of irresponsible willful opening; micro contacts will make students have emotional Dependence, personality disorder, communication fear and other psychological problems, may also be in the virtual environment to relax vigilance, easy to be deceived [3]. These negative effects have inhibited the healthy growth of college students to a great extent. As an important part of College Students' overall quality, media literacy is an essential quality of college students in the media environment in the period of social transformation in China. It plays an important role in promoting the socialization of college students and achieving lifelong learning in a learning society. In recent years, with the continuous progress of media technology and the great influence of media on people, employers have been attaching great importance to media public relations and media marketing, and more and more attention has been paid to media literacy of college students. Therefore, the high media literacy is the necessary condition for the college students in the new era to go to the society smoothly.

\subsection{The internal demand of university culture construction}

The popularization of media literacy in college students, the promotion of the overall development of college students, the function of modern universities and the goal of the national quality education. The existence of university is to inherit, propagate and create culture, so as to "promote the socialization, individuation and civilization of the educated, so as to create healthy people and perfect people". In the era of mass media, the media literacy training for college students in the media flooded society is essentially the implementation of quality education that enables college students to become more complete and perfect. It is a quality citizen education. The popularity of media literacy education in Colleges and universities, opens up a channel to know the world and to obtain information for college students, in the process of the appropriate use of the media to enrich their life and learning, the connotation of university culture development and change with the times and constantly enrich the students cultural function, but also more perfect. This influence is not limited to teachers and students, but is limited to the campus [4]. It will exert immeasurable influence on the development of all social citizens and the whole nation's culture.

\subsection{The inevitable choice of Ideological and political education in colleges and universities}

On the one hand, the traditional mode of Ideological and political education is impacted. The traditional model is the use of teaching materials through classroom for students to carry out ideological indoctrination, and micro media all media era of development, so that the micro media become the college students' learning essential life and emotional exchange platform, while the traditional model can not reach the field is insufficient. This requires the ideological and political education of college students to keep pace with the times and innovate constantly, and to explore and utilize the micro media as a tool for education [5]. On the other hand, it has also added new content to the ideological and political education of college students. There are strong contrasts and contradictions between the idealized virtual world constructed by the Internet and the rational world based on the Internet, such as micro-blog and WeChat. How to properly handle the contrast between the virtual and the reality in order to guide the college students reasonably is the realistic problem facing the ideological and political education in Colleges and universities. The new education proposition of media literacy training can solve the above problems. Developing media literacy training for college students is an important supplement to the content of Ideological and political education in Colleges and universities, and it can enhance their initiative, pertinence and timeliness.

\subsection{The strategic requirements for improving the quality of Higher Education}

Whether it is the modernization of education, the perfection of quality standard system or the improvement of educational quality, the starting point and foothold are all based on human beings and promote the all-round development of college students. The era is developing, and the quality and extent of College Students' quality is constantly improving and expanding. Therefore, the all-round development of college students must synchronize with the times [6]. The content of overall development should also enrich with the development of the times. With the rapid 
development of science and technology, media literacy undoubtedly enriched and enriched the connotation of quality education, and the corresponding training practice should become an important part of improving the quality of higher education in an all-round way. In the era of mass media, improving the media literacy of college students and strengthening the training of College Students' media literacy are of great strategic importance for improving our higher education system, improving the quality of higher education, and promoting the development of higher education with the times [7].

\section{The Path Exploration of Media Literacy Training for College Students in the Media Age}

\subsection{Establish and improve the relevant laws and regulations of the media}

At present, the network space is chaotic, crime is rampant, because of the lack of relevant regulations. Therefore, to establish a good network order, first to work, establish and improve relevant laws and regulations, to adhere to the law office, media, media governance according to law in accordance with the law of the media, so that the micro media healthy running track on the rule of law, let the public standard own laws and regulations under the constraints of the behavior. Secondly, we should establish and improve the relevant moral norms, carry out the publicity of the moral norms of the media, and make full use of the ethical and moral norms of the people's words and deeds [8]. The rule of law and rule of virtue in the media complement each other, therefore, to regulate the network behavior of the public, establish a good network order, we must vigorously promote the socialist core values, with the excellent traditional culture of the Chinese nation and the world civilization results of conservation mass media moral cultivation, purification of micro media virtual space, optimize the micro ecological environment of media.

\subsection{Guiding the production, management and management of media products with the correct value coordinates}

General secretary Xi Jinping pointed out: "network business to develop, must carry out the development of thought of" taking people as the center, according to the "active use, scientific development, according to management, to ensure the safety of the train of thought", therefore, to guide the production and management of the mass media in the handling of two relations: one is to handle the problem the relationship between ideology and consumer entertainment, two is a good economic and social benefits of the dialectical relationship. For the ideology and the consumption of entertainment, ideology refers to the media in the public opinion guidance should adhere to the principles of socialism, promoting the value of the mainstream view of socialism can not deviate from the direction of socialism; consumer entertainment refers to the media business behavior as a business behavior, its products as a commodity, to meet the public's consumption so to take into account the consumer demand, media entertainment in compliance with the socialist ideology. For the economic and social benefits, economic benefits is refers to the medium itself is for the purpose of profit, the media needs to produce media products to obtain economic benefits to maintain their normal operation and profit; social benefit refers to the media as a public product or public tools, should bear the social responsibility, fulfill their social obligations [9]. Media information content and communication to promote the social theme and social positive energy. Therefore, when we pay attention to the economic benefits of media products, we must not be slaves to the market, not to be full of copper odor, but also to achieve social benefits, and social benefits must be put first. For a long time, there has been a lack of work on the standards of information release and the form of content presentation of the mass media. Mass media supervision and supervision organs should not only supervise the production and operation of media, but also emphasize the conscientiousness and normalization of mass media's initiative to shoulder corresponding social responsibilities. Through publicity and education, improve the occupation moral level of industry personnel, to the construction of spiritual civilization fundamental policy oriented, to develop specific management system, clear to employees and institutions of rewards and punishment; punishment of dishonesty, misconduct, the default behavior of production and operation, to encourage mass media units to 
carry out all kinds of public advocacy activities.

\subsection{Construction of the teachers' team of media literacy training for college students}

The curriculum model (phenotype to establish special curriculum plan and organize the implementation of media literacy education teachers), which is mainly composed of Journalism Professional teachers. Because the teachers of the journalism and communication major are rich in professional knowledge and rich in teaching practice. At the same time, we can also recruit senior editors and journalists from the media to serve as a part-time media literacy training teacher. For the invisible curriculum mode (the media literacy content in other courses or ablation penetration, implementation) requires the establishment of professional training institutions and in-service training platform, skills and methods of cultivating specialized media literacy of university teachers, the training methods are: the establishment of specialized training base for each district, responsible for regular professional training organizations; the establishment of training network platform for network distance training [10]. Training can be combined with the specific circumstances of full-time determine training duration and the training way or not. As long as teachers adhere to self-learning and sensitivity to relevant knowledge, and integrate strategies into teaching, it is entirely competent for the teaching task of media literacy training. If the topic is organized, the training of media literacy should be done by professional media literacy, so there will be no need for media literacy training for the teachers who belong to it. Teachers who undertake two different courses should have different requirements in every aspect of training, but training for professional courses of teacher education is essential. This will help to improve the quality of the media teachers and effectively improve the students' media literacy in the teaching.

\subsection{Giving full play to the auxiliary role of campus media and practical activities}

First of all, the university campus radio, newspapers, websites and other media resources, with its information to the students, the target audience, and higher frequency of contact, a daily life in college media environment, expand the media literacy training channels, special reports, to popularize media knowledge, create atmosphere. Secondly, the various student organizations as the main organizer and student activities, to provide a good platform for the media practice of college students, with its strong appeal, organize students to carry out various activities to the practice of communication, media literacy as the theme of the essay topics, such as: media literacy, media literacy seminars and publicity the media literacy of viewing and so on, can make students become the main media practice activities to enrich the life experience of media. Finally, as the media protagonist of the media age, micro-blog and WeChat are indispensable campus media resources. Colleges and universities can create official micro-blog and WeChat public numbers. Media literacy training teachers or teachers of Ideological and political work can disclose micro-blog and micro signals, and try to get the attention of the majority of students. Through micro-blog and WeChat, the theme of media literacy training is published. It guides students to use media correctly, interpret media content and identify bad information consciously. Using useful information, we know how to use the media to meet many aspects of our needs in learning, life and work, so as to help college students grow to be thoughtful, opinionated, cultural and quality citizens.

\subsection{Provide excellent, quotient, healthy content and culture}

First of all, media organizations should strictly control the media products to prevent the spread of media products. In the market economy, the operation of media organization is essentially a commercial activity. Information is the commodity that it produces. The pursuit of the maximization of economic interests is the essence of its nature, and profit is the first priority of its survival. It is in the interest of the drive, the media information in the media age is not homogeneous and widespread. Therefore, college students should interpret and analyze the information objectively and use the media carefully when they accept and transmit the media information. But the fact is that due to the low level of media literacy, low psychological maturity and poor self-control ability, it is difficult for them to effectively control and control their media use behavior. In this state, it should be the root of the source to solve the problem, that is to say, the media agency in charge of 
information editing, manufacturing and dissemination shall strictly fulfill their social responsibilities, to strict standards, in the production of layers of review media information, media information to prevent flooding, so as to avoid the adverse negative impact on Information College students. To solve the problem of the spread of information from the source media organization, has a fundamental solution effect, to nip in the bud, provide the true quality of the media information and good media environment for college students. Secondly, the media should provide excellent, elegant and healthy content and culture to eliminate vulgarity, violence and yellow content. In twenty-first Century, the development of the media industry China quickly, "however in the market economy" will ", various media gradually lost their immunity and alienation". "Some culture media for the pursuit of commercial interests, lost their cultural position and post responsibility, ignore the educational function of culture and moral responsibility, to give up the aesthetic value of culture, or to vulgar kitsch, and create a good cultural environment and draw further apart the atmosphere of the mission. In short, in the current media development environment, we choose "media literacy training" as a topic to reiterate the importance of media literacy training, and build a framework that is not only academic but also practical. It is of great value to improve our media literacy training and ideological and political education discipline system, broaden our academic vision, clarify misunderstandings, promote the practice of media literacy training with Chinese characteristics, and optimize the media environment in China.

\section{References}

[1] Ashley S, Lyden G, Fasbinder D. Exploring Message Meaning: A Qualitative Media Literacy Study of College Freshmen. [J]. Journal of Media Literacy Education, 2012, 4(3):229-243.

[2] Babad E, Peer E, Hobbs R. Media literacy and media bias: Are media literacy students less susceptible to nonverbal judgment biases? [J]. Psychology of Popular Media Culture, 2012, 1(2):97-107.

[3] Liu L M, Qin G W, Department A. An Empirical Study of the New Media Literacy of Leading Cadres: Taking the Cadre Training Students of Anhui Province as an Example [J]. Journal of Anhui Agricultural University, 2013.

[4] Schmidt H C. Media Literacy Education from Kindergarten to College: A Comparison of How Media Literacy Is Addressed across the Educational System. [J]. Journal of Media Literacy Education, 2013, 5:295-309.

[5] Rackaway C. The Path to Informed Citizenship: Curricular and Co-Curricular Media Literacy Efforts in American State Colleges and Universities [J]. 2013, 2(2).

[6] Bajpai Y. Community Reading Room (Public Library) as an Instrument in Eradication of Adult Illiteracy: A Case Study of Eritrea (North East Africa) [J]. International Journal of Library Science, 2013, 2(2):26-42.

[7] Mackay S, Heck E. Life storytelling at the ABC: Challenges of 'giving the audience a voice' in the context of public service media [J]. 2015, 7(1).

[8] Mohamed H S. The Use of Social Media Among Public Relations Students in the UAE [J]. International Journal of Customer Relationship Marketing \& Management, 2015, 6(2):15-30.

[9] Bermejo R. How do politicans react to crisis times? Public Opinion, Media Coverage and Immigration Policy Reforms in Britain and Spain [J]. Journal of the Acm, 2018, 9(1):61-63.

[10] Guo W C, Lai F C. Media bias, slant regulation, and the public-interest media [J]. Journal of Economics, 2015, 114(3):291-308. 